\title{
Tocando o prematuro: significado para auxiliares e técnicas de enfermagem
}

\author{
Touching the premature: the meaning for nurse's aides and technicians \\ Tocar el prematuro: significado para auxiliares y técnicos de enfermería
}

\author{
Carla Caniatto Perencin', Circéa Amália Ribeiro" \\ ' Universidade Nove de Julho. São Paulo-SP, Brasil. \\ " Universidade Federal de São Paulo, Departamento de Enfermagem. São Paulo-SP, Brasil.
}

Submissão: 08-04-2010 Aprovação: 13-12-2011

\section{RESUMO}

Este estudo objetivou compreender o significado de tocar o prematuro, durante a prestação do cuidado, para auxiliares e técnicas de enfermagem. Utilizaram-se, como referencial teórico, o Interacionismo Simbólico e, como referencial metodológico, a Teoria Fundamentada nos Dados (Grounded Theory). Os dados foram coletados por meio de observação participante e entrevistas semiestruturadas com três auxiliares e duas técnicas de enfermagem. A análise comparativa dos dados levou à identificação da categoria conceitual Promovendo o bem-estar e o cuidado do bebê por meio do toque, a qual permitiu compreender que as funcionárias consideram o toque como a base do cuidado, reconhecendo-o como integrante dos cuidados diários; e empreendem ações de tocar o bebê no sentido de promover o seu bem-estar.

Descritores: Enfermagem pediátrica; Recém-nascido prematuro; Toque; Neonatologia.

\section{ABSTRACT}

This study aimed to understand the meaning of touching the premature, in the nursing care, for nursing aides and technicians. The Symbolic Interaction was used as theoretical reference and the Grounded Theory as methodological reference. Data were collected through observation and semi-structured interviews, carried out with three nursing aides and two technicians. Data analysis was carried out until leading to the identification of the conceptual category Enhancing the baby's welfare and care through touch, representing the meaning of touching the premature for the nursing aides and technicians, who consider touch as the basis of caring, recognising it as part of the daily care and performing the action of touching as a way to enhance the baby's welfare.

Key words: Pediatric nursing; Premature newborn baby; Touch; Neonatology.

\section{RESUMEN}

Este estudio tuvo como objetivo comprender el significado de tocar el prematuro, en el contexto del cuidado, para auxiliares y técnicos de enfermería. Fueron utilizados como referencial teórico y metodológico el Interacionismo Simbólico y la Teoria Fundamentada em los Datos (Grounded Theory). Los datos fueron colectados por médio de observación participante y entrevistas semiestructuradas, con tres auxiliares y dos técnicas. El análisis de los datos fue dirigida llevano la identificación de la categoría conceptual Buscando el bienestar y el cuidado del prematuro por médio del toque, lo cual permitió comprender que las funcionárias lo consideram como base del cuidado y integrante de los cuidados, y ejecutan la acción de tocar com la finalidad de promover su bienestar.

Palabras clave: Enfermería pediátrica; Recién nacido prematuro; Toque; Neonatología. 


\section{INTRODUÇÃO}

Em Neonatologia, comunicamo-nos de modo constante com o bebê, utilizando intensamente a comunicação não verbal, ou seja, aquela que ocorre na interação pessoa-pessoa por meio de gestos, posturas, expressões faciais e pelo toque. Os sinais não verbais emitidos pelos prematuros precisam ser valorizados pelos profissionais de enfermagem, para que estes identifiquem e interpretem os que podem ser decorrentes de dor ou alterações do estado de saúde do bebê, a fim de que as providências do cuidado possam ser tomadas(1).

Dentre as formas de comunicação não verbal, destaca-se a tacêsica, que envolve o estudo do toque e suas características, podendo demonstrar afeto, envolvimento, segurança e valorização do ser humano ${ }^{(2)}$.

Existem três tipos de toque: o expressivo que ocorre espontaneamente, promovendo contato afetivo e não faz parte dos procedimentos; o instrumental, que visa ao contato físico deliberado, requerido para desenvolver um procedimento específico e o expressivo-instrumental que é uma combinação dos dois outros tipos de toques ${ }^{(3)}$.

Em se tratando da assistência ao recém-nascido prematuro, o conhecimento e o aprimoramento constante desse tipo de linguagem são fundamentais e devem ser integrados à assistência. Sua utilização tem sido preconizada nas últimas décadas, tendo como importante pesquisadora a Doutora Tiffany Field, cujos estudos constatam um ganho de peso ponderal mais rápido em prematuros massageados sistematicamente, levando a uma diminuição considerável do número de dias de internação e, conseqüentemente, redução dos custos hospitalares ${ }^{(4)}$.

Outros estudos advertem para o fato de que os recém-nascidos prematuros são particularmente vulneráveis à elevada tensão muscular e postulam que, para seu particular estado de desenvolvimento neuromuscular, eles devem ser abraçados e acalentados de forma tão constante quanto no útero ${ }^{(5)}$.

Como enfermeiras com experiência assistencial em Unidade de Terapia Intensiva Neonatal, temos observado que a execução de procedimentos realizados com o recém-nascido prematuro, mostra-se, em geral, extremamente mecânica, ou seja, as tarefas são executadas sem considerar suas reações e sem estabelecimento de outra interação com ele, além do toque instrumental exigido pelo procedimento. Nem sempre, também, os profissionais de saúde proporcionam o toque afetivo, demonstrativo de carinho, afeto e segurança, extremamente necessário ao crescimento e desenvolvimento desses bebês.

Com base nessa observação, surge nossa preocupação a respeito de como toda esta situação poderá afetar o neonato, uma vez que a conscientização da importância do tipo de toque oferecido ao recém-nascido torna-se fundamental no cuidar com qualidade para o alcance de uma assistência de enfermagem humanizada e de qualidade.

Será que ao interagir com tantas rotinas e realizar procedimentos, além da grande habilidade manual exigida para a assistência, os profissionais de enfermagem têm a consciência do quanto o toque influencia as experiências que o neonato pré-termo levará para o resto da vida? O quanto percebem que podem contribuir para melhorar a qualidade das experiências do toque oferecido aos recém-nascidos durante sua permanência no hospital e participando de seu desenvolvimento?

Buscando responder a essas inquietações, realizamos este estudo com o objetivo de compreender o significado atribuído pelo auxiliar e técnico de enfermagem ao ato de tocar o recém-nascido prematuro, no contexto do cuidado de enfermagem.

\section{MÉTODO}

A natureza do estudo foi qualitativa e utilizou o Interacionismo Simbólico-IS como referencial teórico e a Teoria Fundamentada nos Dados - TFD (Grounded Theory) como referencial metodológico. O IS concentra seus estudos na natureza das interações, na dinâmica das atividades sociais entre as pessoas, no significado atribuído aos eventos de acordo com o mundo em que vivem no seu cotidiano, ou nas ações por elas desempenhadas ${ }^{(6)}$. A TFD é uma metodologia de pesquisa que utiliza um conjunto de procedimentos sistematizados, buscando desenvolver uma teoria acerca de um fenômeno, levando à emergência de explicações teóricas para os eventos subjetivos da experiência humana ${ }^{(7)}$.

O estudo foi realizado na Unidade de Prematuros de uma instituição privada situada na cidade de São Paulo, composta de seis leitos, na qual ficam internados os prematuros nascidos na instituição, que se encontram em condições mais estáveis, podendo estar em incubadora ou berço, necessitando ou não de suporte de oxigênio, sem uso de medicação endovenosa, recebendo alimentação por sonda ou em transição para via oral, e que são conhecidos como prematuros em período de "engorda".

Participaram da pesquisa três auxiliares e duas técnicas de enfermagem que prestavam assistência ao recém-nascido prematuro nos diferentes plantões: manhã, tarde e noite. Todas possuíam nível de escolaridade médio completo, sendo que as duas técnicas cursavam a Graduação em Enfermagem.

Este número de participantes foi determinado pelo processo de amostragem teórica e, à medida que os dados iam sendo analisados, novas hipóteses eram levantadas e novos dados coletados, até que se verificou a saturação, ou seja, que os dados tornaram-se repetitivos, não aparecendo novos dados e observou-se crescente compreensão dos conceitos identificados ${ }^{(8-9)}$.

Os dados foram coletados no período de julho de 2004 a março de 2005 após aprovação do projeto pelo Comitê de Ética em Pesquisa da UNIFESP, sob o processo número 0255/04 e também autorizado pela diretoria da instituição na qual ocorreu a coleta, bem como as profissionais que participaram do estudo assinaram o Termo de Consentimento Livre e Esclarecido.

As estratégias empregadas para a coleta dos dados foram a observação participante e a entrevista semi-estruturada. A primeira foi realizada no sentido de observar como as funcionárias agiam e interagiam com os bebês prematuros, ou seja, como elas os abordavam e de que maneira os tocavam durante a prestação dos cuidados de enfermagem, como o banho, a 
alimentação via oral ou por sonda, o posicionamento ao seio materno, a troca de fralda, entre outros.

As entrevistas foram realizadas individualmente, tiveram duração de 35 a 50 minutos e iniciaram-se com a seguinte questão norteadora: Como é para você a vivência de tocar o prematuro, durante a prestação de cuidados de enfermagem? No desenrolar das entrevistas, foram formulados outros questionamentos no sentido de buscar aprofundar a compreensão dos conceitos que estavam sendo expressos pela entrevistada. As entrevistas foram gravadas e transcritas na íntegra.

A análise dos dados foi acontecendo concomitantemente à coleta dos mesmos, de forma comparativa e constante. Seguindo os passos preconizados pela TFD, a análise iniciou-se pela Codificação Aberta, que consiste na identificação e análise cuidadosa dos dados e conceituação dos mesmos em forma de códigos. A seguir, realizou-se a Categorização que é o processo de agrupar conceitos que pertencem a um mesmo fenômeno, constituindo-se as categorias. Após, as categorias foram comparadas entre si, reorganizadas, agrupadas e reduzidas, permitindo a emergência de categorias que expressassem um conceito mais amplo e abstrato, com suas subcategorias e componentes. Essa etapa de análise denominada Codificação Teórica constitui-se por um intenso movimento indutivo e dedutivo do pesquisador e se caracteriza pela densificação e reagrupamento de categorias que expressem conceitos similares, até obter sua saturação(9-10).

Vale ressaltar que a TFD configura-se em um processo de contínua construção, podendo ser interrompida em qualquer uma das etapas, sem incorrer em um erro metodológico(11). Assim, embora esta metodologia se proponha à elaboração de um modelo teórico, este estudo foi conduzido até a Codificação Teórica que levou à construção de uma Categoria Conceitual representativa do fenômeno do estudo.

\section{RESULTADOS}

A análise comparativa dos dados levou à emergência da Categoria Conceitual "Promovendo o Bem-Estar e o Cuidado do Bebê por Meio do Toque" (Figura 1) a qual revela o significado atribuído à experiência de tocar o recém-nascido prematuro, para as auxiliares e técnicas de enfermagem, permitindo compreender que durante a interação com o bebê, essas profissionais têm um propósito estabelecido para o ato de tocar que é, principalmente, promover o cuidado e o bem-estar do recém-nascido prematuro. A seguir, as categorias que compõem esta experiência: Tocando para cuidar, Favorecendo a interação com o bebê, Promovendo o bem-estar para o bebê, Reconhecendo condições para o tocar e Sentindo-se gratificada serão apresentadas e exemplificadas com dados extraídos das observações e das entrevistas das profissionais participantes.

A primeira categoria Tocando para cuidar expressa a percepção que as funcionárias têm do toque, enquanto uma ação de cuidar, e a importância que elas Ihe atribuem no contexto do cuidado diário prestado ao bebê, enquanto a base do cuidado. Revela também que elas valorizam o modo como os bebês devem ser tocados no momento em que estão realizando os procedimentos, acreditando que, com isso poderão estar, inclusive, favorecendo o desenvolvimento dos mesmos.

"Ao mesmo tempo em que eu estou tocando, estou cuidando".(E 3)

"... quando o neném fica com muita dificuldade para mamar, a gente faz um toque, mais de face. A gente acaricia mais, mexe mais com a criança, para dar estímulo a ele para mamar. Eu acho que é uma forma de toque, né?

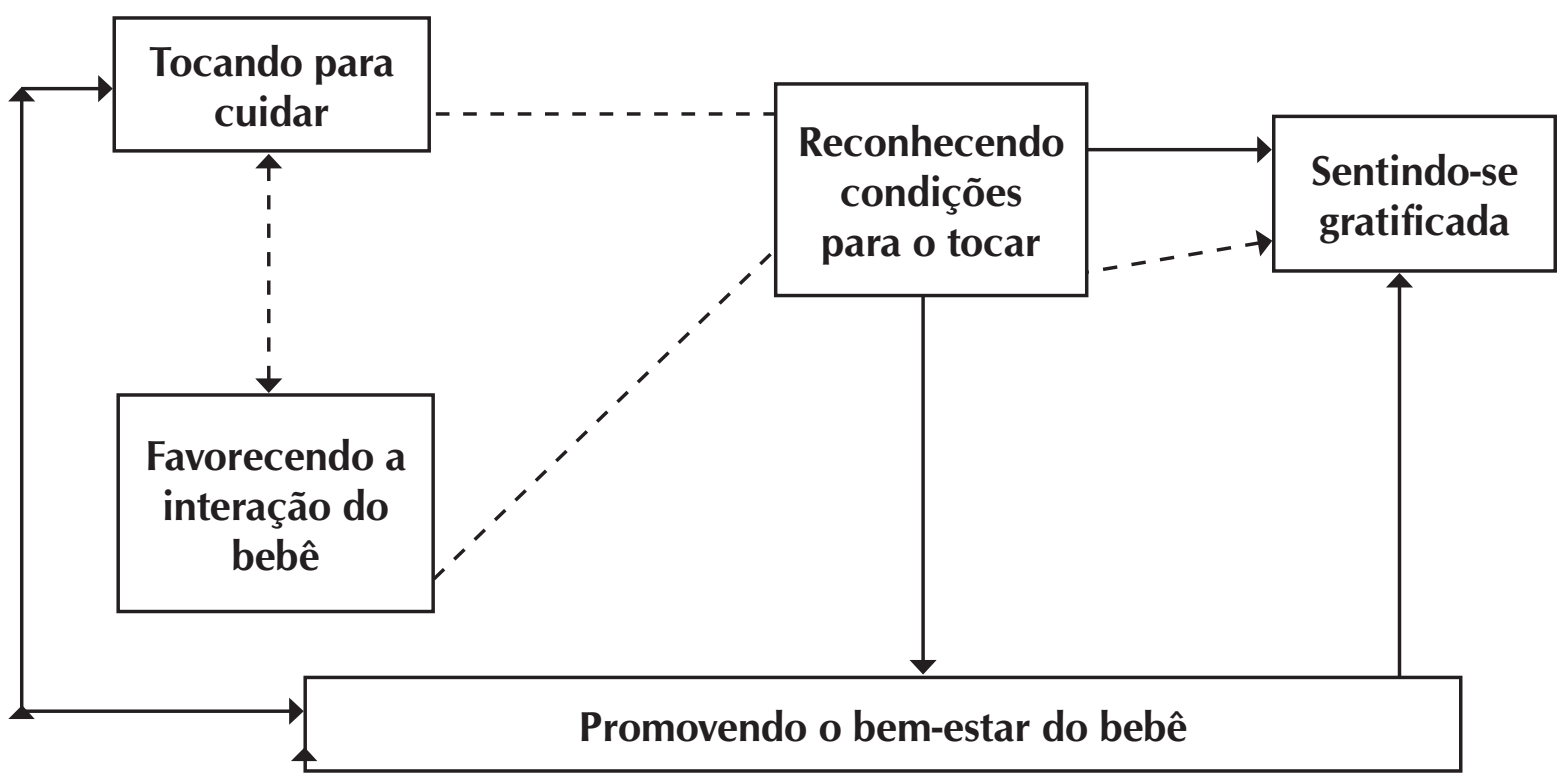

Figura 1: "Promovendo o Bem-Estar e o Cuidado do Bebê por Meio do Toque". 
Lógico que você está ali acariciando, mas, pensando que ele precisa mamar..."(E5)

"... o bebê cresce muito bem, tem desenvolvimento bem melhor psicomotor. O toque é importante para tudo, não só a cabecinha dele, mas a parte motora. Ele vai se desenvolver melhor."(E5)

Esta preocupação com o bebê é tão grande, que as funcionárias rezam para que eles se recuperem, integrando o toque à oração. Elas também se colocam no papel da pessoa da mãe tocando-os como se fossem as mesmas.

“... é como se eu fosse a mãe daquela criança, naquele momento..."(E1)

"... eu posso colocar minhas mãos... e fazer uma oração e pedir: Deus coloca tua unção nas minhas mãos..."(E3)

No entanto, as funcionárias reconhecem que nem sempre o toque que ocorre durante o cuidado é bom para o prematuro. Consideram a realização de procedimentos invasivos como necessária, mas também como uma das piores formas de toque dada aos bebês, pois elas percebem que é péssimo para eles.

“... você dá uma picada, numa criança, que seja para coIher um exame. Eu acho que é a pior forma. Essa forma de toque, com certeza, eles não gostam de jeito nenhum. Eu acho que é uma das piores. "(E5)

Ao mesmo tempo, em que o toque está integrado ao cuidado, ele é considerado um importante instrumento de interação, conforme é expresso na categoria Favorecendo a interação com o bebê. As funcionárias conseguem identificar as reações dos bebês e passam a conhecer cada um, a partir do comportamento que eles expressam ao serem tocados e quando ao mesmo tempo conversam com eles, integrando, assim, a comunicação verbal e não verbal.

"Eu sinto que ele gosta deste carinho que a gente dá. Mesmo se não é carinho, ele sente esse contato com a nossa mão, com o colo. Eu não sei bem dizer por que, mas eles se sentem felizes. Eu acho que é a forma que eles mais sentem. Não sei se eles já entendem nessa fase, mas é importante, eles ouvirem o que a gente fala, como a gente toca neles".(E2)

A terceira categoria, Promovendo o bem-estar do bebê, revelou-se a grande meta do cuidado para as funcionárias. Elas vêem o toque como uma ação de promoção desse bem-estar, que está presente durante toda a prestação de cuidados. Assim, tocam cuidadosamente os bebês como algo muito precioso e no sentido de estar promovendo conforto, carinho e assegurando sua proteção.

“... você pega o bebezinho como se tivesse pegando uma pérola, uma coisa muito preciosa"(E4)
"Ajudar a dar carinho, a tocar aquele bebê, no momento que você está fazendo aquele toque agressivo, ao mesmo tempo você vai acalentar o bebê ..."(E2)

"... e vai pegar as perninhas do bebezinho, sempre deixa um dedo entre as perninhas que é para não comprimir uma na outra, que pode oferecer um desconforto ..."(E4)

Elas também percebem a necessidade de tocá-los, quando eles manifestam sensação de desconforto, em especial, durante a realização de procedimentos dolorosos, como durante a punção venosa. Assim, enquanto uma funcionária punciona o bebê, a outra estimula a sucção não nutritiva com o dedo envolto em luva, ao mesmo tempo em que conversa com o mesmo tentando acalmá-lo.

"Olha bebezinho, chupa o dedinho da titia, você vai ficar bom rapidinho, segura o dedinho da titia." (Observação)

Buscando promover o bem-estar do bebê, as funcionárias identificam nos pais importantes aliados e preocupam-se em orientá-los como devem tocar seus filhos, no sentido de favorecer interação entre eles, para que os bebês se sintam bem.

"Inclusive eu até explico para as mamães: oh! ofereça um movimento que para ele é mais aconchegante, que vai ser assim, como se fosse ninando, para ele dormir".(E3)

A quarta categoria, por sua vez, revela que as funcionárias também vão Reconhecendo condições para o tocar durante o processo de cuidado e identificam condições que favorecem e as aquelas que dificultam o ato de tocar. Nesse sentido, elas acreditam que o estar bem do profissional, seu estado emocional, sua percepção e personalidade, bem como as condições físicas em que os bebês se encontram e as próprias condições de trabalho influenciam o modo de elas tocarem o bebê.

"Você precisa estar bem também, né? Se você vai lá todo estressado, não sei se vai resolver muita coisa."(E4)

"Porque já aconteceu de eu estar verificando temperatura, cuidando do bebê, e a outra colega está conversando com você, e você também está conversando com ela um assunto que não tem nada a ver com o bebê, ele chora."(E3)

"Posso fazer o mesmo tipo de trabalho que o seu, mas a gente é diferente, a nossa maneira de tocar, de cuidar."(E5)

"Quando os bebês estão mais estáveis, dá mais segurança, mais tranqüilidade e é mais prazeroso."(E1)

"Os profissionais não têm muito tempo para ficar com essa criança por mais tempo, pra dar um carinho maior"(E5)

A última categoria desvela que em decorrência de tocarem os bebês para a promoção do seu bem-estar, as auxiliares e técnicas de enfermagem vivenciam sentimentos de prazer e 
conforto, Sentindo-se gratificadas. Elas sentem prazer em tocar a pele dos bebês que é tão macia e sentem-se muito bem com isso, pois tocá-los, é para elas vivenciar algo maravilhoso e muito gostoso. Além disso, percebem o quanto os bebês também se sentem gratificados por estarem sendo tocados.

"E é gostoso tocar o bebê, né? Tem uma pele assim tão gostosa, né? Eu me sinto bem ..."(E3)

“... e eles se sentem gratificados. E daí pra mim é bom, eu me sinto bem, também".(E4)

\section{DISCUSSÃO}

Os dados deste estudo revelaram que, ao contrário do que nos parecia, as auxiliares e técnicas de enfermagem não só consideram o toque como a base do cuidado com o prematuro, como reconhecem a sua importância e que ele está presente em vários momentos da interação com o bebê. Permitiram também compreender que, ao tocar o prematuro durante o contexto do cuidado, elas estão imbuídas de um objetivo que é promover o bem-estar do bebê. Elas também manifestam a crença, a convicção, que o toque é o promotor deste bem-estar e, assim, o vivenciam durante sua atividade profissional no sentido de estarem Promovendo o Bem-Estar e o Cuidado do Bebê por Meio do Toque.

A partir dessa revelação, compreendemos o quanto as funcionárias acreditam ser o toque o próprio cuidar, pois, quando indagadas a respeito do significado de tocar o bebê, elas respondiam sempre no sentido de uma ação do cuidado, apoiando nossa crença que a assistência prestada ao prematuro pode qualificar-se conforme conseguimos visualizar o toque em meio a tantas rotinas que temos a seguir em uma Unidade de Cuidados aos Recém-nascidos Prematuros.

Tal fato vem ao encontro do pensar de outros autores, segundo os quais o toque e o cuidado são inseparáveis, devendo fazer parte do plano de cuidados do cliente e ser considerado uma intervenção do profissional de enfermagem ${ }^{(12)}$. Da mesma forma, consideram que humanidade da enfermeira é revelada pelo modo carinhoso do seu toque, fala através das mãos, palavras vindas de seu interior, do seu coração(13).

Os achados desta pesquisa também evidenciaram a preocupação das funcionárias de enfermagem em tocarem o bebê prematuro para que ele se desenvolva. A efetividade do toque para a promoção do desenvolvimento vem sendo enfatizado por inúmeros estudiosos, segundo os quais o desenvolvimento neuropsicológico é mais bem percebido, quando os bebês são tocados durante a estada no hospital ${ }^{(4,14)}$. Assim, deveríamos incorporar, sistematicamente, o toque e outras medidas de promoção do desenvolvimento na assistência e sermos veículo de orientação e apoio aos pais que cuidarão deste prematuro em casa.

Consideramos que os profissionais de enfermagem podem ser facilitadores da interação entre o bebê e sua família, visto que a apreensão dos sinais não verbais do bebê, e o conhecimento das peculiaridades de cada um podem ser transmitidos à família com o objetivo de favorecer seu desenvolvimento e facilitar a interação entre ambos ${ }^{(13)}$. Nesse sentido, conforme demonstraram os achados deste estudo, as auxiliares e técnicas de enfermagem pesquisadas observam e conhecem o comportamento de cada bebê, cabendo a nós, enfermeiros, orientá-las no sentido de prover os fundamentos científicos relativos ao manuseio do prematuro, facilitando sua organização e desenvolvimento.

Concordamos que o conhecimento científico deve ser introduzido na prática assistencial de maneira a ser absorvido por todos os profissionais que atuem com estes bebês, facilitando assim o acesso à literatura específica(15).

Segundo o manual do Programa Mãe Canguru, devemos atentar para a utilização dos cuidados contingentes com o bebê, o que exige uma observação prévia, análise da real necessidade dos procedimentos, realização dos mesmos no momento mais adequado ao bebê e organizado de modo modulado, de acordo com suas respostas ${ }^{(16)}$.

Os dados deste estudo reforçam que as funcionárias se preocupam o tempo todo em fazer com que o bebê sinta-se bem, utilizando vários artifícios afetuosos para este propósito, o que encontra respaldo na literatura, a qual enfatiza que na condição de mães substitutas, as funcionárias utilizam algumas de suas habilidades pessoais, como a sensibilidade e a percepção na interação com a criança, mostram comportamentos verbais e não verbais como meios para transmitirem carinho à criança ${ }^{(5)}$. A assistência pode adquirir uma qualidade completamente diferente, quando fazemos uso de atributos como a sensibilidade, afetividade, empatia e compreensão, que se transmitem por meio dos cuidados de diferentes naturezas: afetivos, objetivos ou mesmo técnicos ${ }^{(17)}$.

A esse respeito, em nossa experiência profissional, temos constatado o quanto o toque afetivo pode mesmo contribuir para a melhoria da qualidade de cuidado ao bebê, pois observamos que ele chora menos durante uma punção venosa, se alguém o consola, o que fica evidenciado pela redução de demonstração de mal-estar, representados pelos movimentos desordenados dos membros e pelo franzir da testa, o que também é percebido pelas funcionárias, participantes do estudo.

Adicionalmente, acreditamos que a percepção das funcionárias em estabelecer a comunicação com os pais, mesmo que seja com o objetivo de promover o bem-estar do bebê, pode ser o início de um processo de sensibilização da equipe de enfermagem para a inclusão mais efetiva da família no cuidado ao recém-nascido prematuro.

O cuidado centrado na doença, tendo como finalidade a recuperação biológica do prematuro, vem se transformando no sentido de tornar-se um cuidado desenvolvimental individualizado, e também centrado na família, visando à promoção da saúde e à emancipação dos sujeitos; o paradigma biotecnológico vem sendo substituído pelo holismo ${ }^{(18)}$.

Assistir a família é uma inovação tecnológica que vai permitir inscrever o aspecto humanístico nas relações interpessoais entre instituição-bebê e famílias, privilegiando uma prática centrada em novas modalidades de relação para o alcance efetivo de uma assistência humanizada e integral à criança e à família(19).

A preocupação com a promoção do bem-estar do bebê evidencia o quanto as funcionárias deste estudo estão sensibilizadas 
neste sentido, e no intuito de melhorar a qualidade do tocar, durante os cuidados do prematuro. Assim, elas relatam aspectos que favorecem a realização do toque durante a assistência prestada a cada bebê, reconhecendo condições para o tocar. Pensamos que o fato de se sentirem bem consigo mesmas e com as outras pessoas faz com que elas tenham maior entusiasmo para o alcance da qualidade na realização das suas tarefas, e, assim, prestem mais atenção ao prematuro como pessoa.

Como enfatiza a literatura, todas as vezes que estamos mais conscientes, cuidamos melhor de nós mesmos e dos outros, de uma forma significativa, no sentido de uma responsabilização com a qualidade e, assim, temos a oportunidade de perceber coisas impressionantes na assistência ${ }^{(17)}$.

Dentro deste panorama, acreditamos que, dependendo da situação com a qual está interagindo, o indivíduo construirá uma percepção de como tocar o bebê em uma determinada situação, influenciada pela memória de outra situação que já foi vivenciada. Neste sentido, a experiência de cuidar de um bebê em uma situação de instabilidade pode gerar desconforto para as funcionárias. Mas, o estado do bebê não é imperativo, pois as profissionais consideram importante o ato de tocá-los, amenizando o possível mal-estar durante o período de instabilidade.

Elas relatam, entretanto, que o tocar o prematuro pode sofrer influência das condições de trabalho a que estão submetidas, confirmando que a diminuição do quadro de pessoal e a superlotação da unidade contribuem significativamente para a ocorrência de distorções no processo de trabalho(20).

Os dados revelados neste estudo também permitiram compreender que, mesmo interagindo com estas dificuldades, o ato de tocar o bebê prematuro é benéfico, tanto para eles como para as funcionárias, que se sentem gratificadas, ao mesmo tempo em que se percebem estar Promovendo o Bem-Estar e o Cuidado do Bebê por Meio do Toque. Corroboramos com a idéia que pertencer a uma Unidade Neonatal requer, além de formação e conhecimentos específicos, um amor incondicional; os profissionais recebem estímulos suficientes para conservar esse sentimento por meio da gratificação sentida, quando constatam a existência de reciprocidade entre o amor materno, amor à causa e à resposta apresentada pelo bebê ${ }^{(21)}$.

\section{CONSIDERAÇÕES FINAIS}

Embora os benefícios do toque sobre o recém-nascido sejam bastante reconhecidos na literatura e no meio acadêmico, salientamos o quanto foram surpreendentes as revelações deste estudo, evidenciando que as auxiliares e técnicas de enfermagem já se encontravam sensibilizadas para a importância do toque, estando já prontas para interagirem com a importância do tocar os bebês prematuros sob o ponto de vista teórico.

Assim, conhecendo a realidade de atendimento ao recém-nascido prematuro de cada serviço, nós, enfermeiras, podemos ser facilitadoras e prover subsídios, para que nossas funcionárias sedimentem esse conhecimento no sentido que o toque seja utilizado durante o cuidado por meio de ações sistematizadas, o que promoverá a melhora da qualidade de atendimento a este bebê.

Ressaltamos, ainda, que conforme os pressupostos da TFD a categoria conceitual emergida neste estudo poderá ser ampliada e modificada a partir da construção de outros grupos amostrais, incluindo a participação do enfermeiro ou de funcionários de enfermagem de outras realidades hospitalares, no sentido de possibilitar a construção de um modelo teórico representativo do significado de tocar o recém-nascido prematuro para a equipe de enfermagem.

\section{REFERÊNCIAS}

1. Pinheiro EM. Sendo mediada pela força da motivação: o significado da comunicação para as profissionais de enfermagem na interação com o recém-nascido e a família [Tese]. São Paulo (SP): Universidade de São Paulo-Escola de Enfermagem; 2003.

2. Silva MJP. Comunicação tem remédio: a comunicação nas relações interpessoais em saúde. São Paulo: Gente; 1996.

3. Watson $\mathrm{WH}$. The meanings of touch: geriatric nursing. J. Communication 1975; 25(3): 104-12.

4. Field TM. Preterm infant massage therapy studies: an american approach. Semin Neonatol 2002;7:487-94.

5. Rice RD. The effects of the rice infant sensorimotor stimulation treatment on the development of high-risk infants. Newborn Behavioral Organization: Nursing Research and Implications 1979;15(7):7-26.

6. Charon JM. Simbolic Interactionism. $3^{\text {a }}$ ed. Engleward Cliffs: Prentice-hall; 1989.
7. Pettengill MAM, Ribeiro CA. A teoria fundamentada nos dados. In: Matheus MCC, Fustinoni SM. Pesquisa qualitativa em enfermagem. São Paulo: Livraria Médica Paulista Editora; 2006.

8. Ribeiro CA, Ângelo M. O significado da hospitalização para a criança pré-escolar: um modelo teórico. Rev Esc Enferm USP 2005;39(4):391-400.

9. Strauss AL, Corbin J. Basics of qualitative research: grounded theory procedures and techniques. California: Sage; 1991.

10. Glaser BG. Theoretical sensitivity. Mill Valley: The Sociology Press; 1978.

11. Castro AS. Compreendendo o significado da vivência da cirurgia de postectomia para o pré-escolar [dissertação]. São Paulo (SP): Universidade de São Paulo-Escola de Enfermagem; 2001.

12. Silva MJP. O toque e a distância interpessoal entre enfermeiros e pacientes nas consultas de enfermagem. Rev. Esc. Enferm. USP 1991;25(3):309-18. 
13. Rolim KMC, Cardoso MVLML. O discurso e a prática do cuidado ao recém-nascido de alto risco: refletindo sobre a atenção humanizada. Rev. Latino-Am. Enfermagem 2006;14(1):85-92.

14. Glover V, Onozawa K, Hodgkinson A. Benefits of infants massage for mothers with postnatal depression. Semin. Neonatol 2002; 7:495-500.

15. Scochi CGS, Carletti M, Nunes R, Furtado MCC, Leite AM. A dor na Unidade Neonatal sob a perspectiva dos profissionais de enfermagem de um hospital de Ribeirão Preto-SP. Rev. Bras. Enferm. 2006;59(2):188-94.

16. Ministério da Saúde (BR). Secretaria de Políticas de Saúde. Área de Saúde da Criança. Atenção humanizada ao recém-nascido de baixo peso: método mãe-canguru. Brasília: Ministério da Saúde; 2002.

17. Silva MGB. Massageando bebês: a singularidade da experiência [dissertação]. São Paulo(SP): Universidade de São Paulo-Escola de Enfermagem; 2000.

18. Scochi CGS, Kokuday MLP, Riul MJS, Fonseca LMM, Leite AM. Incentivando o vínculo mãe-filho em situação de prematuridade: as intervenções de enfermagem no Hospital das Clínicas de Ribeirão Preto. Rev Latino-Am Enfermagem 2003; 11(4): 539-43.

19. Gaíva MAM, Ferriani MGC. Prematuridade: vivências de crianças e familiares. Acta Paul. Enferm. 2001;14(1):17-27.

20. Vernier ETN, Dall'agrol CM. (Re) ações de uma equipe de enfermagem mediante a permanência conjunta em pediatria. Acta Paul. Enferm. 2004;17(2):172-80.

21. Barbosa VL. O vínculo afetivo na UTI Neonatal: uma questão de reciprocidade da tríade mãe-prematuro-equipe de enfermagem [tese]. São Paulo (SP): Universidade Federal de São Paulo/EPM; 1999. 